\title{
Can-Pain-a digital intervention to optimise cancer pain control in the community: development and feasibility testing
}

\author{
Rosalind Adam ${ }^{1}$ (D) Christine M. Bond ${ }^{2} \cdot$ Christopher D. Burton ${ }^{3} \cdot$ Marijn de Bruin $^{4} \cdot$ Peter Murchie $^{2}$
}

Received: 22 January 2020 / Accepted: 5 May 2020 / Published online: 28 May 2020

(C) The Author(s) 2020

\begin{abstract}
Purpose To develop a novel digital intervention to optimise cancer pain control in the community. This paper describes intervention development, content/rationale and initial feasibility testing.

Methods Determinants of suboptimal cancer pain management were characterised through two systematic reviews; patient, caregiver and healthcare professional (HCP) interviews $(n=39)$; and two HCP focus groups $(n=12)$. Intervention mapping was used to translate results into theory-based content, creating the app "Can-Pain". Patients with/without a linked caregiver, their general practitioners and community palliative care nurses were recruited to feasibility test Can-Pain over 4 weeks.

Results Patients on strong opioids described challenges balancing pain levels with opioid intake, side effects and activities and communicating about pain management problems with HCPs. Can-Pain addresses these challenges through educational resources, contemporaneous short-acting opioid tracking and weekly patient-reported outcome monitoring. Novel aspects of Can-Pain include the use of contemporaneous breakthrough analgesic reports as a surrogate measure of pain control and measuring the level at which pain becomes bothersome to the individual.

Patients were unwell due to advanced cancer, making recruitment to feasibility testing difficult. Two patients and one caregiver used Can-Pain for 4 weeks, sharing weekly reports with four HCPs. Can-Pain highlighted unrecognised problems, promoted shared understanding about symptoms between patients and HCPs and supported shared decision-making.

Conclusions Preliminary testing suggests that Can-Pain is feasible and could promote patient-centred pain management. We will conduct further small-scale evaluations to inform a future randomised, stepped-wedge trial.

Trial registration Qualitative research: ClinicalTrials.gov, reference NCT02341846

Feasibility study: NIHR CPMS database ID 34172
\end{abstract}

Keywords Cancer $\cdot$ Pain $\cdot$ Palliative care $\cdot$ Health informatics $\cdot$ Intervention mapping $\cdot$ Behaviour change

\section{Background}

Electronic supplementary material The online version of this article (https://doi.org/10.1007/s00520-020-05510-0) contains supplementary material, which is available to authorized users.

Rosalind Adam

rosalindadam@abdn.ac.uk

1 Academic Primary Care, Institute of Applied Health Sciences, University of Aberdeen, Room 1:020, Polwarth Building, Foresterhill, Aberdeen AB25 2ZD, UK

2 Academic Primary Care, Institute of Applied Health Sciences, University of Aberdeen, Aberdeen, Scotland, UK

3 Academic Unit of Primary Medical Care, University of Sheffield, Sheffield, England, UK

4 Health Psychology, Radboud University Medical Centre, Radboud Institute of Health Sciences, IQ Healthcare, Nijmegen, Netherlands
Cancer incidence and prevalence rates are increasing [1]. Pain affects over a third of patients with cancer and over two thirds of patients with advanced cancer [2]. Cancer pain is distressing for patients and their families and is a frequent reason for hospital admissions and emergency department utilisation [3]. Pain is the most frequent reason for calls to out-of-hours primary care services by people with cancer $[4$, 5]. Individuals have difficulties communicating about pain, judging when to seek help and using prescribed analgesics effectively [6]. Pain and symptom control are achieved more often in inpatient and hospice settings than within the community [7].

There is increasing political interest in novel interventions that support individuals to be cared for safely, effectively and efficiently within the community $[8,9]$. It has been proposed 
that digital technologies will increasingly support patients to communicate with the health service and to participate more actively in their care [9]. In oncology, digital technologies have been used to capture patient-reported outcome measures (PROMs) and to feed these back to healthcare professionals (HCPs) [10-12].

Two systematic reviews showed that PROM feedback can improve patient satisfaction with care and increase the number of symptoms discussed during consultations [13, 14]. Another review [15] found that PROM feedback interventions for cancer pain management reduce patient-reported pain intensity by approximately 1 point out of 10 . The review highlighted problems with intervention fidelity and inadequate attention to how PROMs were integrated within clinical care to improve pain management [15].

Allsop et al. [16] reviewed information communication and technology systems designed for the identification, assessment or monitoring of pain in patients with cancer. Seventeen unique systems were identified. Twelve were for use by patients in clinic waiting rooms prior to appointments. Others collected PROMs by telephone via nurses or automated telephone lines. Only four systems allowed remote monitoring via Web-based forms, and no smartphone apps were identified [16]. Studies lacked detail on the rationale and development approaches taken and did not fully capitalise on the capabilities of digital technologies.

Digital interventions tend to have multiple interacting components [17]. The Medical Research Council (MRC) framework for complex intervention development stipulates that such interventions should identify and utilise existing evidence, theory and model processes and outcomes during the development phases [18].

The aim of this research was to develop a theory and evidence-based intervention to optimise cancer pain management in the community. The objectives were to fully understand the problem and to design an intervention that addressed the needs of those experiencing and managing cancer pain. This paper describes intervention development, intervention content and components, expected mechanisms of action and early feasibility testing.

\section{Methods}

An intervention mapping (IM) approach guided this research project $[19,20]$. IM is an established six-step, problem-based approach which allows behaviour change theory to be applied systematically to a health problem. The steps in IM are as follows: (1) modelling the problem, (2) specifying programme outcomes and objectives and creating a model of change, (3) programme design, (4) programme production, (5) creating a programme implementation plan and (6) planning evaluation. This paper deals with the first four steps.

\section{Step 1: modelling the problem}

Step 1 involves fully characterising the problem and the behaviours involved in suboptimal cancer pain management. Existing literature was reviewed [15, 21], and interviews were conducted with patients with cancer pain $(n=14)$, their linked caregivers $(n=6)$ and HCPs $(n=19)$. Two multidisciplinary HCP focus groups were conducted [22]. Results of interviews and focus groups have previously been reported in detail [22]. Findings that influenced intervention content are summarised here, and a logic model of the problem is illustrated in Fig. 1.

Effective cancer pain management relies on multiple interacting patient and professional behaviours, including interpretation and reporting of pain by patients/accessing help, pain assessment/communicating about pain, analgesic prescribing and patients utilising analgesics optimally.

Patients experiencing problematic cancer pain tended to be prescribed strong opioids [22]. Breakthrough (short-acting "as-required" opioid) analgesic use was often considered to be a surrogate measure of pain control by professionals and was an important consideration during medical reviews. Concerns about opioids, mainly side effects and impact on function, were prominent in people with cancer pain. Patients made complex trade-offs between physical activity levels, pain intensity, analgesic side effects and social functioning in order to achieve individual goals, and did not always communicate these decisions to HCPs.

Managing cancer was highly burdensome for patients and their caregivers, and pain management was one of many competing considerations. A desirable intervention would add value to current management approaches without significantly adding to patient, caregiver or professional workload.

\section{Step 2: specifying programme outcomes and objectives and creating a model of change}

The model of the problem derived in step 1 (Fig. 1) was used to identify a target population and to specify intervention goals, performance objectives (the relevant behaviours to be changed to achieve these goals) and determinants of target behaviours, for example knowledge, attitudes and self-efficacy. A logic model is provided (Online resource 1). The resulting intervention targets individuals prescribed strong opioids.

Intervention goals are to increase the proportion of patients who reported pain intensity levels within their acceptable range, to reduce the proportion reporting problems with opioid analgesics and to improve person-centred care and overall satisfaction with care. Performance objectives include the following: for patients and HCPs to discuss and agree treatment goals; for patients to monitor pain, important side effects, function and breakthrough opioid use; for patients to seek timely medical attention for unacceptable levels of pain; and 


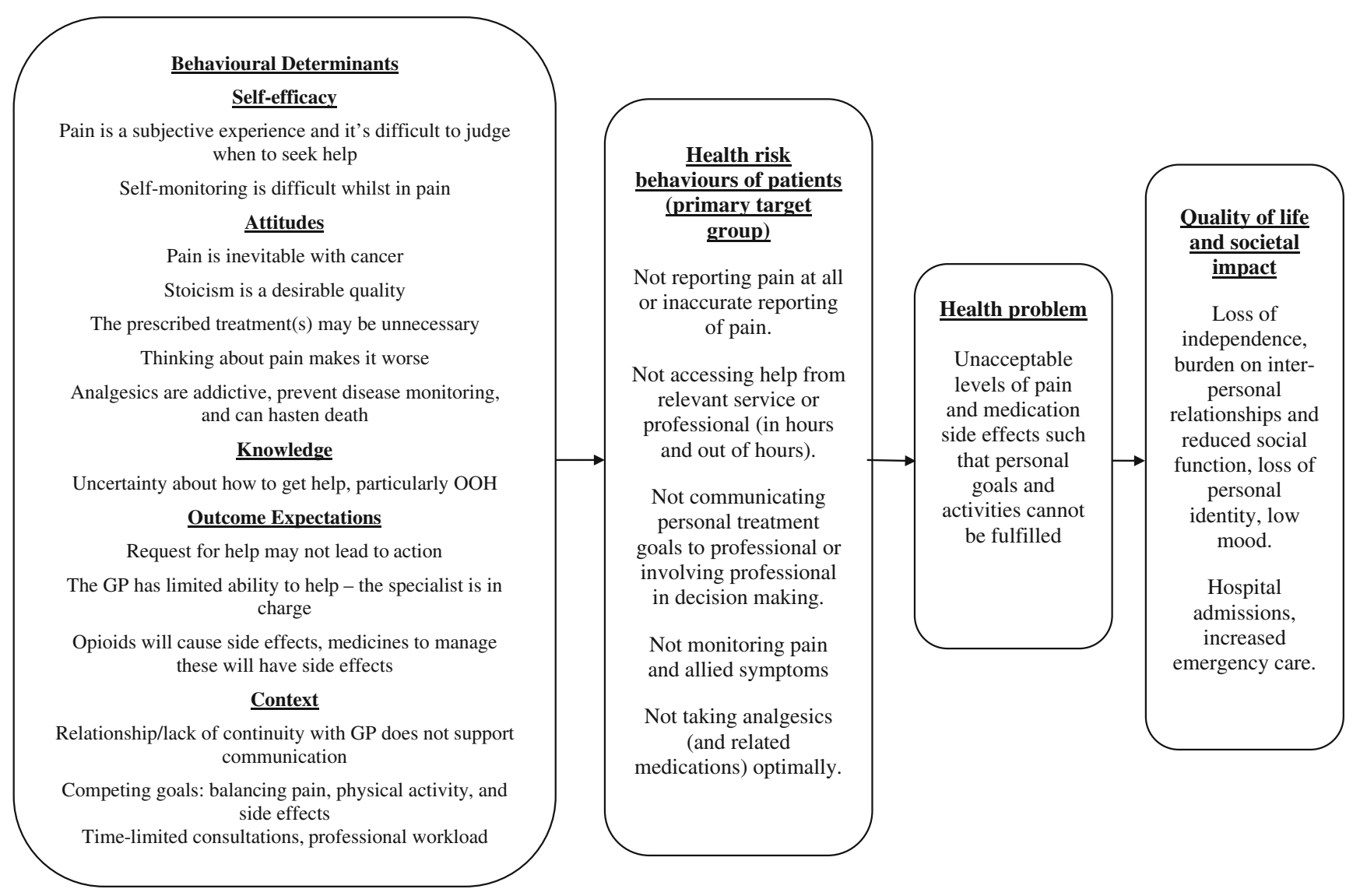

Fig. 1 Logic model of patient behaviours and their determinants that can lead to unacceptable levels of pain and other negative outcomes

for patients and community HCPs to review outcomes and adjust goals.

Behavioural change matrices (Online resource 2) were created, linking important and potentially changeable performance objectives with the behavioural determinants necessary to achieve the objective.

\section{Step 3: programme design}

Creative ideas generated by all authors were assessed objectively against the specified performance objectives and behavioural determinants from step 2. Theoretical methods to change behaviour were chosen from published lists within IM [19]. Methods were selected according to the behavioural determinants to be changed, whilst considering which methods would fit best with practical intervention ideas. Methods underpinning the intervention include goal setting, self-monitoring of behaviour, tailoring and feedback. Further details of theoretical methods and how they fit within the intervention are presented in Table 1. The intervention has two main components: a digital app (Can-Pain) to be used by patients who are prescribed strong opioids, and a consultation with a HCP in which data generated by the app is used to give patients tailored feedback about pain management.

\section{Step 4: programme production}

A pictorial storyboard of Can-Pain was presented to a computer scientist. A mock version of the app was created using Microsoft PowerPoint and taken to healthy volunteers (health psychology students, academic colleagues, multidisciplinary clinicians and delegates at academic conferences). Individuals interacted with the mock app and offered verbal feedback, which was used to refine wording and presentation. CanPain was programmed using Ruby on Rails Web application framework. The current version requires Internet connectivity.

\section{Feasibility testing}

A feasibility study was designed, in which data from four to six patients would be used to test usability, functionality, acceptability to patients/carers/clinicians and feasibility in clinical practice. Several of the planning group had experience of successful feasibility testing digital interventions with a small number of users [23, 24]. It was anticipated that four sets of linked patients, caregivers, nurses and doctors (i.e. 12 participants) would give substantial insights into the intervention experience, participant burden, acceptable duration and dose (e.g. frequency of diary entries, acceptability of diary length 
Table 1 App content, theoretical methods and expected mechanisms of action to improve pain management

\begin{tabular}{llll}
\hline $\begin{array}{l}\text { App section and } \\
\text { technological features }\end{array}$ & $\begin{array}{l}\text { Content and/or educational } \\
\text { messages }\end{array}$ & $\begin{array}{l}\text { Examples of change } \\
\text { objectives addressed (see } \\
\text { Online resource 2) }\end{array}$ & $\begin{array}{l}\text { Theoretical methods to } \\
\text { change behaviour (from } \\
\text { IM) }\end{array}$
\end{tabular}

Rationale/mechanisms through which pain management could be improved

\begin{tabular}{|c|c|c|c|}
\hline $\begin{array}{l}\text { Breakthrough analgesic } \\
\text { recording } \\
\text { Tap screen to quickly record } \\
\text { fast-acting opioid. The app } \\
\text { times and dates the entry } \\
\text { and adds it to the user's } \\
\text { weekly report screen } \\
\text { Users receive a message } \\
\text { asking them to seek help if } \\
\text { pain is not improving in } \\
30 \text { min. An in-app algo- } \\
\text { rithm automatically asks } \\
\text { user to seek medical atten- } \\
\text { tion (and re-directs to a list }\end{array}$ & $\begin{array}{l}\text { User can quickly record } \\
\text { fast-acting breakthrough } \\
\text { opioids, and invited to re- } \\
\text { cord a pain trigger from a } \\
\text { pre-defined list, including } \\
\text { movement, stress and ac- } \\
\text { tivities }\end{array}$ & $\begin{array}{l}\text { Knowledge objective 9: Can } \\
\text { explain important triggers } \\
\text { for pain and how to } \\
\text { manage these. } \\
\text { Self-efficacy objective 9: } \\
\text { Expresses confidence in } \\
\text { judging when to seek help } \\
\text { from professional }\end{array}$ & $\begin{array}{l}\text { Self-monitoring } \\
\text { Feedback } \\
\text { Cue-altering (using the } \\
\text { stimulus of breakthrough } \\
\text { analgesic use to get the } \\
\text { user to consider seeking } \\
\text { early help for } \\
\text { escalating/non-resolving } \\
\text { pain) } \\
\text { Facilitation (linking } \\
\text { messages about seeking } \\
\text { help to lists of telephone } \\
\text { numbers to make seeking } \\
\text { help easier) }\end{array}$ \\
\hline
\end{tabular}

of telephone help num-

bers) if 3 short-acting opi-

oid doses are recorded in

$24 \mathrm{~h}$

Computerised adaptive
Weekly diary

Touch-screen self-rating scales testing is used to tailor questions based on responses; e.g. reporting side effects leads to questions on the nature of side effects. These questions are skipped if side effect ratings are low.

Diary report automatically emailed to pre-specified address at completion

\section{Users self-rate pain (various dimensions) on a $0-10$ point scale. A novel item asks about the level at which pain becomes both- ersome.}

Site of pain can be indicated on an interactive body map, and word clouds contain descriptive terms, e.g. words that describe neuropathic pain, "pins and needles", etc.

Users are asked about mood, medication side effects, concerns about opioids, missed analgesic doses and reasons for missing doses.

Users can enter free text information

\footnotetext{
View diary reports

Natural language generation used to make bespoke reports from the diary and breakthrough entries, including visual summaries/graphs
}

Patients can view their breakthrough analgesic reports and weekly diary reports at any time
Video about pain
management
An actor represents a patient Knowledge objective 3: Can with cancer pain. The

explain different
Self-efficacy objective 1: Is Feedback

able to recognise and

describe characteristics of

their pain, exacerbating

and relieving factors,

triggers and personal

response to analgesics

Subjective norm objective 5:

Expresses the expectation

that disease and response

to treatment can change

(improve or deteriorate)

over time and that pain

management goals and

plans may need to be

adjusted
Data on the number of short-acting doses is used by clinicians to inform long-acting opioid dose adjustments.

Short-acting opioid dose can give insights into the adequacy of overall pain control.

Patients can be reluctant to seek help, despite experiencing problematic pain - the app gives them specific cues to seek help, and directs them to a screen with useful telephone numbers

Reports are shared with clinicians to inform medical consultations and enhance pain assessment.

The diary summarises the user's current status with respect to pain/related symptom control, and whether users are experiencing levels of pain that are unacceptable to them.

Output report is designed to promote discussion with clinicians about pain management expectations and any discrepancies between patient and professional goals and highlights any attitudinal barriers to analgesic utilisation which could be tackled by the clinician

Insights into trends in pain control and triggers for pain/analgesic use could inform pain management approaches by the patient, e.g. taking an analgesic before a painful activity or recognising that stress/emotions are contributing to pain

Chunking - the video is in sections and has text
Educational messages are directly derived from 
Table 1 (continued)

\begin{tabular}{lllll}
\hline $\begin{array}{l}\text { App section and } \\
\text { technological features }\end{array}$ & $\begin{array}{l}\text { Content and/or educational } \\
\text { messages }\end{array}$ & $\begin{array}{l}\text { Examples of change } \\
\text { objectives addressed (see } \\
\text { Online resource 2) }\end{array}$ & $\begin{array}{l}\text { Theoretical methods to } \\
\text { change behaviour (from } \\
\text { IM) }\end{array}$ & $\begin{array}{l}\text { Rationale/mechanisms } \\
\text { through which pain } \\
\text { management could be } \\
\text { improved }\end{array}$
\end{tabular}

\begin{tabular}{|c|c|c|c|c|}
\hline & $\begin{array}{l}\text { video depicts an interview } \\
\text { between the actor (patient) } \\
\text { and a GP. } \\
\text { The patient discusses his } \\
\text { fears about cancer pain, } \\
\text { expectations about pain } \\
\text { management and how he } \\
\text { has overcome certain } \\
\text { barriers to successful pain } \\
\text { management. The patient } \\
\text { and doctor discuss the } \\
\text { nature of cancer pain, } \\
\text { treatment options, using } \\
\text { short- and long-acting } \\
\text { opioids to control pain, } \\
\text { how to manage side effects } \\
\text { and problems that arise at } \\
\text { night/weekends }\end{array}$ & $\begin{array}{l}\text { examples of how other } \\
\text { patients like them balance } \\
\text { pain, side effects and } \\
\text { participation ability } \\
\text { Outcome expectation } \\
\text { objective 5: Expects that } \\
\text { many side effects can be } \\
\text { managed effectively } \\
\text { Self-efficacy objective 6: Is } \\
\text { able to plan for potential } \\
\text { problems in the } \\
\text { out-of-hours period and } \\
\text { agree an action plan with } \\
\text { community healthcare } \\
\text { professional }\end{array}$ & $\begin{array}{l}\text { descriptions at the end of } \\
\text { each section } \\
\text { Framing and persuasive } \\
\text { communication-- } \\
\text { positive messages are } \\
\text { used to persuade others } \\
\text { to adopt optimal pain } \\
\text { management approach } \\
\text { Imagery - metaphors are } \\
\text { used to aid understanding } \\
\text { Information about others' } \\
\text { approval—-the clinician } \\
\text { emphasises that they ex- } \\
\text { pect to be contacted } \\
\text { about pain management } \\
\text { issues } \\
\text { Modelling - patient (actor) } \\
\text { is age appropriate with } \\
\text { neutral accent and gives } \\
\text { an example of how they } \\
\text { controlled pain }\end{array}$ & $\begin{array}{l}\text { unmet patient needs } \\
\text { elicited from qualitative } \\
\text { enquiries with patients } \\
\text { and existing literature }\end{array}$ \\
\hline Useful Web links & $\begin{array}{l}\text { Links to educational } \\
\text { resources on pain and } \\
\text { symptom management } \\
\text { from reputable } \\
\text { organisations }\end{array}$ & $\begin{array}{l}\text { Knowledge objective 2: Can } \\
\text { describe the available } \\
\text { treatment options to } \\
\text { control pain and their side } \\
\text { effects }\end{array}$ & Facilitation & $\begin{array}{l}\text { Sign-posting to existing } \\
\text { educational resources that } \\
\text { are kept up-to-date } \\
\text { Improving knowledge about } \\
\text { pain management } \\
\text { techniques and treatment } \\
\text { options could optimise } \\
\text { self-management }\end{array}$ \\
\hline Useful telephone numbers & $\begin{array}{l}\text { These include out-of-hours } \\
\text { medical contact numbers } \\
\text { (Scotland) and the } \\
\text { Macmillan nursing ser- } \\
\text { vice. Users are also } \\
\text { reminded to telephone } \\
\text { their own medical practice } \\
\text { during daytime hours }\end{array}$ & $\begin{array}{l}\text { Knowledge objective } 4 \text { : } \\
\text { Knows who to contact in } \\
\text { the community for } \\
\text { assistance with symptom } \\
\text { management }\end{array}$ & Facilitation & $\begin{array}{l}\text { Qualitative interviews in the } \\
\text { out-of-hours setting re- } \\
\text { vealed that some patients } \\
\text { did not know who to } \\
\text { contact for help with pain } \\
\text { control. This feature aims } \\
\text { to facilitate access to } \\
\text { medical care }\end{array}$ \\
\hline
\end{tabular}

and questions, number of scheduled intervention consultations) and how the intervention would perform with respect to the behavioural targets identified during IM.

The World Health Organization suggest between 10 and 100 individuals should be involved in feasibility testing digital health interventions [25]. A more conservative sample size was selected because linked participants were being recruited together, and longitudinal data were being collected. Testing also involved a novel consultation model in a vulnerable patient group, and technical problems were anticipated during initial testing.

Recruitment to feasibility testing took place in four stages: first, Macmillan nurses (community palliative care nurses) were recruited by the research team via local networks. Second, the Macmillan nurse identified patients from their caseload who had cancer pain and were using/starting strong opioids. Third, the nurse approached the patient's general practitioner (GP) to gauge interest in participation. Fourth, eligible patients of GPs who were interested in participating were given study invitation packs by their nurses and invited to reply directly to the research team if they wished to participate. Patients were asked to invite a caregiver to participate alongside them if they wished. Thus, Macmillan nurses, their linked patients and the patient's linked GPs were recruited in triads, with or without a linked caregiver (at the discretion of the patient).

Patients were asked to use Can-Pain over a 4-week period. Can-Pain automatically logged patient breakthrough and diary entries and sent them immediately to a pre-programmed email address. During the study period, the reports were sent by 
email to the lead researcher, who forwarded data on a weekly basis to patients' linked GP and Macmillan nurse. The Macmillan nurse was asked to schedule at least one clinical encounter with the patient.

The lead researcher (RA) gave participants a brief, user-led introduction to the app, and participants were provided with a Samsung Galaxy A7 tablet onto which the app had been loaded. Can-Pain was designed to be intuitive, but usability data were collected during feasibility testing to inform the need for additional training. Participants were given unique logins and passwords.

Patient participants were telephoned by the lead researcher each week to check for any problems and collect verbal feedback (brief telephone interview) about Can-Pain. An in-depth interview was performed at the end of the study with all patient/caregiver and professional participants. All interviews were conducted according to schedules. Brief interviews covered participants' experiences of using the app and any problems experienced, particularly burden or technical issues. End-of-study patient/caregiver interviews probed experiences of using Can-Pain, any barriers to interacting with it and how the app influenced pain management, help-seeking and interactions with healthcare professionals. Professional interviews covered experiences of using the weekly pain/symptom reports, how they influenced care and pros/cons of integrating PROMS within clinical care. All participants were asked for suggestions about how to improve the intervention. All interviews were audio-recorded, transcribed verbatim and analysed using Framework and thematic analysis [26]. Quantitative data from app output reports and from user activity automatically logged by the app were analysed descriptively, and medical notes were reviewed to determine whether/how the intervention had been documented within episodes of primary care.

\section{Ethics}

All participants gave informed consent to participate in qualitative research and feasibility testing. Approvals were granted by North of Scotland Regional ethics committee (qualitative research reference $15 / \mathrm{NS} / 0002$; feasibility testing reference $17 / \mathrm{NS} / 0005$ ) and NHS Research and Development.

\section{Results}

\section{Can-Pain intervention content}

The Can-Pain app contains six sections accessible from a dashboard: breakthrough analgesic recording, a weekly diary, viewable summaries of previous diary and breakthrough reports, a video about pain management, useful Web links and telephone help. A screenshot of the dashboard is shown in
Fig. 2. Intervention content, the theoretical methods employed and the rationale through which pain management could be improved are presented in detail in Table 1.

\section{Feasibility testing}

\section{Recruitment and retention}

Seven Macmillan nurses were recruited by the research team. Of these, two nurses recruited two patients, one linked caregiver and two linked GPs. Five nurses who did not recruit a patient/linked GP took no further part in the study, but all other participants completed the full study.

Patient recruitment was challenging, and delays in app programming and hosting on the secure server reduced time available (within our time-limited project) for feasibility testing from 6 to 4 months. Macmillan nurses had minimal contact with patients who were stable. Nurses were not asked to record patients to whom they informally mentioned the study but noted that unpredictable or rapidly deteriorating health status and admission to hospital were significant barriers to recruitment. Nurses also reported not inviting patients whom they judged might be uninterested in digital technology or the intervention. One patient returned his reply slip and had a GP who consented to participate but deteriorated clinically such that he was unable to participate.

\section{Patient characteristics and their reported pain data}

The demographics of both patient participants are presented in Table 2. Both had bony metastases and were on a combination of long- and short-acting strong opioids and a gabapentinoid.

Patient 1 had little variation in her self-reported pain and side effect ratings over the study period, rating overall pain levels between 6 and 7 out of 10, pain becoming bothersome between 5 and 7 out of 10 and analgesic side effects between 5 and 7 out of 10. She used breakthrough analgesia twice to three times every day, routinely taking a breakthrough dose around $11 \mathrm{pm}$.

Patient 2 also had stable pain ratings, with overall pain between 4 and 5 points out of 10 , and reported considering pain bothersome at 6 out of 10 . His pain ratings never crossed this threshold. He used on average three breakthrough opioid doses per week. Stress, movement and activity were pain triggers.

\section{Insights about the intervention from qualitative interviews}

Qualitative interviews with all participants $(n=7)$ (two GPs, two nurses [one interview each], two patients/one caregiver [four longitudinal interviews each], caregiver/patient [joint interviews]) generated around 4 hours of audio-recorded interview data over 4 weeks. Weekly telephone interviews with 


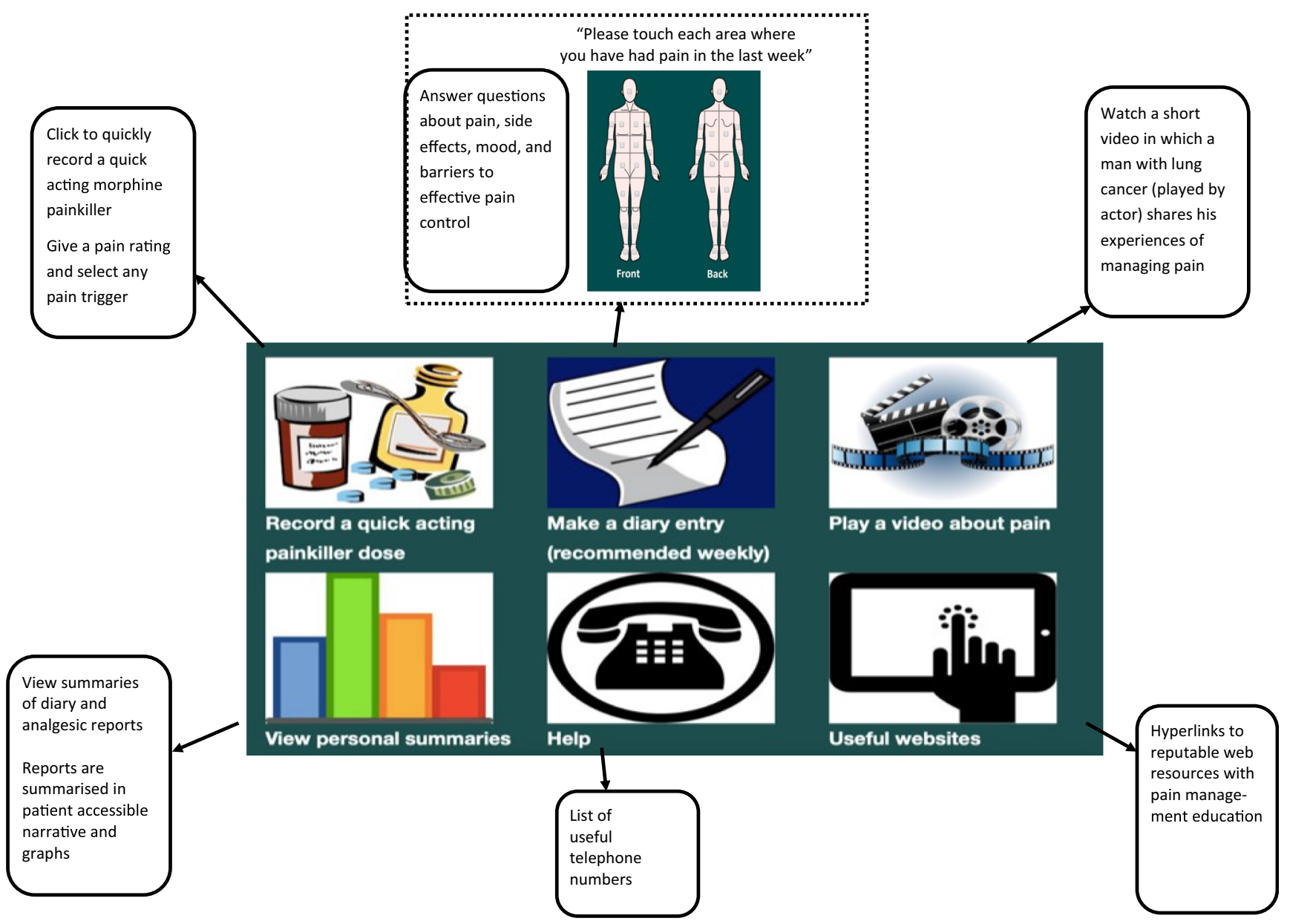

Fig. 2 Annotated screenshot of Can-Pain dashboard

patients/caregiver had an average duration of $15 \mathrm{~min}$. End-ofstudy interviews with patients/caregiver had an average duration of $38 \mathrm{~min}$, with HCP interviews averaging $17 \mathrm{~min}$.

Interviews gave insights into advantages of the intervention, limitations, engagement and usability, technical issues and suggestions for further development.

Patient/caregiver participants felt that being closely monitored was an advantage and judged that their monitoring reports would help their linked HCPs to effectively prioritise their caseload and recognise problems if they arose. They also observed that longitudinal symptom data might be more meaningful to HCPs than assessments at a single point.

Patient 1's reports of consistently high pain scores led to discussions with her HCPs about increasing her analgesic dose, which she was not keen to do. The perceived discordance between problematic pain and patient reluctance to increase analgesia led her professionals to explore the reasons for this, including any concerns about strong opioids.

"What she's recording there is that she's quite plainly sore a lot of the time and the quality of it, you know, she's not happy with being that sore, but then when you actually speak to her (...) "I don't really want to increase my painkillers". And we would explore you know, are you worried about them or anything like that, and not really, (...) I think actually what's going on there is perhaps a larger thing about how she thinks about her illness (...) it's caught up a bit more in her coping mechanisms". (Patient 1's GP)

Patient 2 logged low mood in his diary and reported that stress was a trigger for breakthrough analgesic use, explaining in his study interview that his emotions strongly influenced his perception of pain, but that doctors were more interested in hard facts during time-limited consultations. Reports of patient 2 were used by his GP to start conversations about mood and stress.

"I could easily identify what causes, what triggers him to take a breakthrough, (...) which in his case was mainly stress and it also really highlighted, which perhaps we hadn't identified just quite how he was feeling in himself about the low mood and feeling hopeless at times 
Table 2 Patient participant demographics in feasibility study

\begin{tabular}{|c|c|c|c|c|c|c|c|}
\hline $\begin{array}{l}\text { Patient } \\
\text { number, } \\
\text { sex }\end{array}$ & $\begin{array}{l}\text { Cancer } \\
\text { diagnosis }\end{array}$ & Age & $\begin{array}{l}\text { SIMD } \\
2012 \text { decile } \\
{[43]^{*}}\end{array}$ & $\begin{array}{l}\text { Urban-rural 6- } \\
\text { fold category } \\
{[44]}\end{array}$ & Analgesic regime at enrolment & $\begin{array}{l}\text { Caregiver } \\
\text { participant }\end{array}$ & $\begin{array}{l}\text { Overall pain } \\
\text { rating at } \\
\text { baseline** }\end{array}$ \\
\hline $\begin{array}{r}\text { Patient } 1, \\
\text { female }\end{array}$ & $\begin{array}{l}\text { Metastatic } \\
\text { myeloma }\end{array}$ & 73 & 4 & 1 (large urban) & $\begin{array}{l}\text { Twice daily modified-release hydromorphone, as re- } \\
\text { quired immediate-release hydromorphone, regular } \\
\text { gabapentin }\end{array}$ & $\begin{array}{l}\text { Yes, male } \\
\text { partner }\end{array}$ & 6 \\
\hline $\begin{array}{l}\text { Patient } 2 \text {, } \\
\text { male }\end{array}$ & $\begin{array}{r}\text { Renal cancer } \\
\text { with bony } \\
\text { metastases }\end{array}$ & 55 & 8 & 1 (large urban) & $\begin{array}{l}\text { Twice daily modified-release OxyContin, as required } \\
\text { immediate-release OxyContin, regular pregabalin }\end{array}$ & No & 5 \\
\hline
\end{tabular}

*Scottish Index of Multiple Deprivation (SIMD) 2012 ranks areas in Scotland by postcode from 1 (most deprived) to 6505 (least deprived) according to multiple indicators of deprivation such as employment and housing. Ranks are reported here by decile with 1 indicating most deprived and 10 indicating least deprived

**In-app self-rating where 0 is anchored "no pain" and 10 is anchored "pain as bad as I can imagine"

and worthless, which I was able to use as a cue to discuss those feelings in more detail with him, so I thought that was really beneficial". (Patient 2's GP)

These conversations and references to the app reports were evident in the electronic medical record.

None of the patient or professional participants found the intervention burdensome or onerous. Patient 1's caregiver took charge of app administration, logging her breakthrough doses, asking her to rate pain, reading diary questions to her and entering data on her behalf. The app seemed to be a natural extension to the roles and tasks that he had already adopted as a caregiver.

The main limitation of the intervention from a patient/ caregiver perspective was difficulty summarising a complex phenomenon like pain within a diary that utilised numerical ratings. Word clouds with qualitative descriptions of the pain, and the body map for pain location, helped to an extent, but patients pointed out that several types of pain could co-exist and were difficult to summarise.

There were technical issues during feasibility testing: the app ran slowly at times, there were issues with screen sizing, there were two episodes of a patient being routed to a blank screen after logging an analgesic dose and predictive text features were found to be fiddly. Participants gave suggestions for additional triggers for breakthrough pain that might be included in the next version of the app. Participants would also have liked the ability to $\log$ breakthrough doses retrospectively.

App usage data are presented (Online data source 3). Patient 1/her caregiver logged 62 breakthrough doses over the study period whilst patient 2 logged 13. All sections of the app were utilised over the study period except for the list of telephone help numbers, which was not used by patient 2 .

\section{Discussion}

\section{Main findings}

Patients, their caregivers and HCPs face multiple challenges when managing cancer pain. Can-Pain has been created to support important self-management behaviours. There are early indications that the app is feasible and acceptable to patients, caregivers and HCPs. A key component is feedback of patient-reported data between patients and HCPs. To the best of our knowledge, this is the first digital intervention to use contemporaneous breakthrough analgesic reports as a surrogate measure of pain control and to measure the level at which pain becomes bothersome to the individual. This acknowledges that some patients accept a certain amount of pain and make trade-offs with other important social and functional activities. HCPs used patient reports intuitively to explore patient experiences and treatment goals in depth and to rule out misconceptions about analgesics or their underutilisation.

\section{Context with other literature}

A scoping review of publicly available apps for cancer survivors found that many apps offered symptom tracking and graphing capabilities along with educational information about cancer [27]. None focused specifically on cancer pain. Most were developed by commercial organisations, and some contained content that was potentially exploitative (e.g. selling cures for cancer). Other recognised problems with healthcare apps include lack of scientific/clinician input into content and failure to involve patients in design [28]. Failure to involve patients or to consider complexity can result in technology that does not address important real-world clinical problems, and lack of adoption $[29,30]$.

Other digital interventions exist that support PROM feedback for individuals with symptomatic cancer [10, 12, 31-33]. 
Some provide Web-based pain management advice [34], deliver psychological therapies or support for individuals with cancer pain $[35,36]$ or focus on specific situations such as post-surgical pain management [37]. Most psychoeducational and PROM feedback interventions can achieve small reductions in pain intensity, and it is difficult to know which components are effective [21].

\section{Strengths, limitations and issues still to be established}

Patients and clinicians were involved in intervention development. Intervention components were selected based on behavioural principles, supported by behavioural theories. This should make Can-Pain easy to replicate and protect core intervention components from becoming outdated as technology evolves [38].

The target population for Can-Pain is at risk of unpredictable deterioration and is difficult to recruit into clinical research [39-41]. Our feasibility study design contributed to recruitment difficulties. We relied upon busy nurses to recruit patients and their linked GPs. The multistep recruitment process added complexity. Furthermore, nurses' main clinical workload involved patients who were deteriorating. They had less contact with well patients.

In feasibility testing, both patients had stable pain due to bony metastases, were white Scottish, lived in urban environments and were on similar analgesic regimens. It will be essential to gather further data about how CanPain performs in patients with diverse demographic characteristics. Preliminary findings also suggest that caregivers play a key role in supporting loved ones to manage cancer and pain management. In this study, caregivers were recruited optionally via patients. An alternative strategy would be to recruit caregivers directly, via cancer support organisations for example. Further research is required to fully delineate the role of caregivers in promoting engagement with the intervention and whether caregivers influence the PROM data collected.

\section{Next steps}

A commercial partner will be engaged to optimise the app technically and to make it compatible with major app stores. In eHealth research, there is an argument that software should be continually improved and updated based on user feedback and that every version is a "beta version" [38]. This can make traditional randomised controlled trials impractical. In the next phases of research, collaborations will be formed with hospices, third-sector organisations and researchers in other geographical settings to perform multiple small-scale evaluations. Taken together, these will give major insights into usability and feasibility of Can-Pain and help to establish the most important outcome measures for a future trial.

Outcomes will likely relate to patient-centred care, perceived control and satisfaction. It could also be possible to embed short, validated measurements of pain, quality of life and performance status into the intervention. Numerical 0 to 10-point pain rating scales were unpopular with both patients who took part in feasibility testing, whereas descriptive words were more intuitive. It would be prudent to consider embedding categorical measures of pain with verbal descriptors in addition to numerical ratings.

Burden was a major theme in formative research. Treatment burden (the workload of healthcare and its impact on patient function) is emerging as a major concern globally, particularly for individuals with multimorbidity. There are now several validated measurement tools to assess treatment burden (for example, a 10-item scale by Duncan et al. [42]) which could provide important insights into any added burden of embedding Can-Pain into routine care.

Ultimately, it will be important to test the efficacy and costeffectiveness of Can-Pain. An advantage of digital technology is that it is rapidly scalable. A randomised step-wedged implementation trial with embedded economic evaluation could be an efficient design through which Can-Pain could be simultaneously implemented and evaluated in the community.

\section{Conclusion}

Can-Pain has been designed systematically with input from key stakeholders. Core components are underpinned by theories from behavioural science. Can-Pain could be a promising way of using PROMs to enhance the management of patients with symptomatic cancer within the community setting. We anticipate that Can-Pain could help professionals to recognise problems and could help patients and professionals communicate efficiently about subtler aspects of pain control, without causing unacceptable burden. We will design the next stages of testing to take account of a target population who are seriously unwell and to exploit the accessible and scalable nature of digital technology.

Acknowledgements The authors would like to acknowledge the patients, their caregivers and clinicians who volunteered their time to contribute to intervention development and testing, and Stephanie Inglis, a computer scientist, who completed software programming for the intervention.

Funding information This work was supported by the Chief Scientist Office (CSO), Scottish Government (grant number CAF/14/02), and sponsored by the University of Aberdeen. Neither the funders nor the sponsors had any role in the study design, data collection, data analysis, decision to publish or preparation of the manuscript 


\section{Compliance with ethical standards}

Conflict of interest The authors declare that they have no conflicts of interest.

Open Access This article is licensed under a Creative Commons Attribution 4.0 International License, which permits use, sharing, adaptation, distribution and reproduction in any medium or format, as long as you give appropriate credit to the original author(s) and the source, provide a link to the Creative Commons licence, and indicate if changes were made. The images or other third party material in this article are included in the article's Creative Commons licence, unless indicated otherwise in a credit line to the material. If material is not included in the article's Creative Commons licence and your intended use is not permitted by statutory regulation or exceeds the permitted use, you will need to obtain permission directly from the copyright holder. To view a copy of this licence, visit http://creativecommons.org/licenses/by/4.0/.

\section{References}

1. Maddams J, Utley M, Møller H (2012) Projections of cancer prevalence in the United Kingdom, 2010-2040. Br J Cancer 107:11951202

2. van den Beuken-van Everdingen MH, Hochstenbach LM, Joosten EA, Tjan-Heijnen VC, Janssen DJ (2016) Update on prevalence of pain in patients with cancer: systematic review and meta-analysis. J Pain Symptom Manage 51:1070-1090.e9

3. Vandyk AD, Harrison MB, Macartney G, Ross-White A, Stacey D (2012) Emergency department visits for symptoms experienced by oncology patients: a systematic review. Support Care Cancer 20: 1589-1599

4. Adam R, Wassell P, Murchie P (2014) Why do patients with cancer access out-of-hours primary care? A retrospective study. Br J Gen Pract 64:e99-104

5. Mills S, Buchanan D, Guthrie B, Donnan P, Smith B (2019) Factors affecting use of unscheduled care for people with advanced cancer: a retrospective cohort study in Scotland. Br J Gen Pract 69:e860e868

6. Adam R, Clausen MG, Hall S, Murchie P (2015) Utilising out-ofhours primary care for assistance with cancer pain: a semistructured interview study of patient and caregiver experiences. $\mathrm{Br}$ J Gen Pract 65:e754-e760

7. Office for National Statistics. National Survey of Bereaved People (VOICES) by NHS Area Team (England) - Office for National Statistics (2014) Available from: https://www.ons.gov.uk/ peoplepopulationandcommunity/healthandsocialcare/ healthcaresystem/bulletins/nationalsurveyofbereavedpeoplevoices/ 2014-03-06

8. The Scottish Government. eHealth Strategy 2014-2017 [Internet]. Available from: http://www.gov.scot/Publications/2015/03/5705/ downloads

9. Watcher R. Making IT work: harnessing the power of health information technology to improve care in England. Report of the National Advisory Group on Health Information Technology in England. 2016

10. Ruland CM, Holte HH, Roislien J, Heaven C, Hamilton GA, Kristiansen J, Sandbaek H, Kvaloy SO, Hasund L, Ellison MC (2010) Effects of a computer-supported interactive tailored patient assessment tool on patient care, symptom distress, and patients' need for symptom management support: a randomized clinical trial. J Am Med Inform Assoc 17:403-410
11. Ruland CM, Andersen T, Jeneson A, Moore S, Grimsbo GH, Borosund E et al (2013) Effects of an internet support system to assist cancer patients in reducing symptom distress: a randomized controlled trial. Cancer Nurs 36:6-17

12. Berry DL, Hong F, Halpenny B, Partridge A, Fox E, Fann JR, Wolpin S, Lober WB, Bush N, Parvathaneni U, Amtmann D, Ford R (2014) The electronic self report assessment and intervention for cancer: promoting patient verbal reporting of symptom and quality of life issues in a randomized controlled trial. BMC Cancer $14: 513$

13. Chen J, Ou L, Hollis SJ (2013) A systematic review of the impact of routine collection of patient reported outcome measures on patients, providers and health organisations in an oncologic setting. BMC Health Serv Res 13:211

14. Kotronoulas G, Kearney N, Maguire R, Harrow A, Di Domenico $\mathrm{D}$, Croy S et al (2014) What is the value of the routine use of patient-reported outcome measures toward improvement of patient outcomes, processes of care, and health service outcomes in cancer care? A systematic review of controlled trials. J Clin Oncol 32: $1480-1501$

15. Adam R, Burton CD, Bond CM, de Bruin M, Murchie P (2017) Can patient-reported measurements of pain be used to improve cancer pain management? A systematic review and meta-analysis. BMJ Support Palliat Care 7:0 doi https://doi.org/10.1136/ bmjspcare-2016-001137, 00.1, 0000

16. Allsop MJ, Taylor S, Mulvey MR, Bennett MI, Bewick BM (2015) Information and communication technology for managing pain in palliative care: a review of the literature. BMJ Support Palliat Care 5:481-489. https://doi.org/10.1136/bmjspcare-2013-000625

17. Ahern DK, Patrick K, Phalen JM, Neiley JD (2006) An introduction to methodological challenges in the evaluation of eHealth research: perspectives from the Health e-Technologies Initiative. Eval Program Plann 29:386-389

18. Craig P, Dieppe P, Macintyre S, Michie S, Nazareth I, Petticrew M et al (2008) Developing and evaluating complex interventions: the new Medical Research Council guidance. BMJ 29:337-a1655

19. Bartholomew L, Markham CM, Ruiter RAC, Fernandez ME, Kok G, Parcel GS (2016) Planning health promotion programs: an intervention mapping approach. Fourth Ed. San Francisco: John Wiley \& Sons

20. Fernandez ME, Ruiter RAC, Markham CM, Kok G (2019) Intervention mapping: theory- and evidence-based health promotion program planning: perspective and examples. Front Public Health 7:209. https://doi.org/10.3389/fpubh.2019.00209

21. Adam R, Bond C, Murchie P (2015) Educational interventions for cancer pain. A systematic review of systematic reviews with nested narrative review of randomized controlled trials. Patient Educ Couns 98:269-282

22. Adam R, de Bruin M, Burton CD, Bond CM, Giatsi Clausen M, Murchie P (2018) What are the current challenges of managing cancer pain and could digital technologies help? BMJ Support Palliat Care 8:204-212

23. Burton C, Szentagotai Tatar A, McKinstry B, Matheson C, Matu S, Moldovan R, Macnab M, Farrow E, David D, Pagliari C, Serrano Blanco A, Wolters M, for the Help4Mood Consortium (2016) Pilot randomised controlled trial of Help4Mood, an embodied virtual agent-based system to support treatment of depression. J Telemed Telecare 22:348-355

24. Murchie P, Allan JL, Brant W, Dennis M, Hall S, Masthoff J et al (2015) Total skin self-examination at home for people treated for cutaneous melanoma: development and pilot of a digital intervention. BMJ Open 5:e007993

25. World Health Organisation | Monitoring and evaluating digital health interventions. (2016) Available from: http://www.who.int/ reproductivehealth/publications/mhealth/digital-healthinterventions/en/ 
26. Ritchie J, Lewis J (2003) Qualitative research practice a guide for social science students and researchers, vol 1. Sage, London

27. Adam R, McMichael D, Powell D, Murchie P (2019) Publicly available apps for cancer survivors: a scoping review. BMJ Open 9:e032510

28. Machado GC, Pinheiro MB, Lee H, Ahmed OH, Hendrick P, Williams C, Kamper SJ (2016) Smartphone apps for the selfmanagement of low back pain: a systematic review. Best Pract Res Clin Rheumatol 30:1098-1109

29. van Velthoven MH, Wyatt JC, Meinert E, Brindley D, Wells G (2018) How standards and user involvement can improve app quality: a lifecycle approach. Int J Med Inform 118:54-7. A

30. Greenhalgh T, Wherton J, Papoutsi C, Lynch J, Hughes G, A'Court $\mathrm{C}$ et al (2017) Beyond adoption: a new framework for theorizing and evaluating nonadoption, abandonment, and challenges to the scale-up, spread, and sustainability of health and care technologies. J Med Internet Res 19:e367

31. Kroenke K, Theobald D, Wu J, Norton K, Morrison G, Carpenter J, Tu W (2010) Effect of telecare management on pain and depression in patients with cancer: a randomized trial. JAMA 304:163-171

32. Taylor S, Allsop MJ, Shaw J, Bennett MI, Jones R, Bewick BM (2015) The feasibility of collecting patient reported pain data using a system delivered across four modes of technology. Pain Med 16: 2212-2213

33. Dy SM, Roy J, Ott GE, McHale M, Kennedy C, Kutner JS, Tien A (2011) Tell Us: a Web-based tool for improving communication among patients, families, and providers in hospice and palliative care through systematic data specification, collection, and use. J Pain Symptom Manag 42:526-534

34. Steel JL, Geller DA, Kim KH, Butterfield LH, Spring M, Grady J, Sun W, Marsh W, Antoni M, Dew MA, Helgeson V, Schulz R, Tsung A (2016) Web-based collaborative care intervention to manage cancer-related symptoms in the palliative care setting. Cancer 122:1270-1282

35. Somers TJ, Abernethy AP, Edmond SN, Kelleher SA, Wren AA, Samsa GP et al (2015) A pilot study of a mobile health pain coping skills training protocol for patients with persistent cancer pain. J Pain Symptom Manage 50:553-558

36. Dorfman CS, Kelleher SA, Winger JG, Shelby RA, Thorn BE, Sutton LM, Keefe FJ, Gandhi V, Manohar P, Somers TJ (2019)
Development and pilot testing of an mHealth behavioral cancer pain protocol for medically underserved communities. J Psychosoc Oncol 37:335-349

37. Darnall BD, Ziadni MS, Krishnamurthy P, Flood P, Heathcote LC, Mackey IG, et al (2019) "My surgical success": effect of a digital behavioral pain medicine intervention on time to opioid cessation after breast cancer surgery - a pilot randomized controlled clinical trial. Pain Med 2019 doi/https://doi.org/10.1093/pm/pnz094/ 5488546

38. Baker TB, Gustafson DH, Shah D (2014) How can research keep up with eHealth? Ten strategies for increasing the timeliness and usefulness of eHealth research. J Med Internet Res 16:e36

39. Jordhøy MS, Kaasa S, Fayers P, Underland G, Ahlner-Elmqvist M, Ahlner-Elmqvist M (1999) Challenges in palliative care research; recruitment, attrition and compliance: experience from a randomized controlled trial. Palliat Med 13:299-310

40. LeBlanc TW, Lodato JE, Currow DC, Abernethy AP (2013) Overcoming recruitment challenges in palliative care clinical trials. J Oncol Pract 9:277-282

41. Riopelle D, Wagner GJ, Steckart J, Lorenz KA, Rosenfeld KE (2011) Evaluating a palliative care intervention for veterans: challenges and lessons learned in a longitudinal study of patients with serious illness. J Pain Symptom Manag 41:1003-1014

42. Duncan P, Murphy M, Mann MS, Chaplin K, Gaunt D, Salisbury C (2018) Development and validation of the Multimorbidity Treatment Burden Questionnaire (MTBQ). BMJ Open 8:e019413

43. Scottish Government. Scottish Index of Multiple Deprivation [Internet]. [cited 2019 23rd December]. Available from: https:// www2.gov.scot/Topics/Statistics/SIMD

44. Scottish Government. 2016 urban rural classification. Classification identifying urban and rural areas based on settlement size and drive times. [Internet]. [cited 2019 23rd December]. Available from: https://www.gov.scot/publications/scottish-government-urbanrural-classification-2016/pages/2/

Publisher's note Springer Nature remains neutral with regard to jurisdictional claims in published maps and institutional affiliations. 